\title{
Effects on cardiovascular disease risk of a web-based health risk assessment with tailored health advice: a follow-up study
}

This article was published in the following Dove Press journal:

Vascular Health and Risk Management

8 February 20II

Number of times this article has been viewed

Ersen B Colkesen ${ }^{1,2}$

Bart S Ferket ${ }^{2,3}$

Jan GPTijssen'

Roderik A Kraaijenhagen ${ }^{2}$

Coenraad $\mathrm{K}$ van Kalken ${ }^{2}$

Ron JG Peters'

'Department of Cardiology, Academic Medical Center, University of Amsterdam, Amsterdam, the Netherlands; ${ }^{2}$ NDDO Institute for Prevention and Early Diagnostics (NIPED), Amsterdam, the Netherlands; ${ }^{3}$ Department of Epidemiology,

Erasmus Medical Center,

Rotterdam, the Netherlands
Correspondence: Ron JG Peters Department of Cardiology, F3-236, Academic Medical Center,

University of Amsterdam, PO Box 22660,

II 00 DD Amsterdam, the Netherlands

Tel +3| 205666952

$\mathrm{Fax}+3$ I 205669747

Email r.j.peters@amc.uva.nl
Introduction: A large proportion of the cardiovascular disease (CVD) burden can potentially be prevented by primary prevention programs addressing major causal risk factors. A Web-based health risk assessment (HRA) with tailored feedback for individual health promotion is a promising strategy. We evaluated the effect on CVD risk of such a program among employees of a Dutch worksite.

Methods: We conducted a prospective follow-up study among 368 employees who voluntarily participated in a Web-based HRA program at a single Dutch worksite in 2008. The program included a multicomponent HRA through a Web-based electronic questionnaire, biometrics, and laboratory evaluation. The results were combined with health behavior change theory to generate tailored motivational and educational health advice. On request, a health counseling session with the program physician was available. Follow-up data on CVD risk were collected 1 year after initial participation. The primary outcome was a change in Framingham CVD risk at 6 months relative to baseline. We checked for a possible background effect of an increased health consciousness as a consequence of program introduction at the worksite by comparing baseline measurements of early program participants with baseline measurements of participants who completed the program 6 months later.

Results: A total of 176 employees completed follow-up measurements after a mean of 7 months. There was a graded relation between CVD risk changes and baseline risk, with a relative reduction of $17.9 \%(P=0.001)$ in the high-risk category (baseline CVD risk $\geq 20 \%$ ). Changes were not explained by additional health counseling, medication, or an increase in health consciousness within the company.

Conclusions: Voluntary participation in a Web-based HRA with tailored feedback at the worksite reduced CVD risk by nearly $18 \%$ among participants at high CVD risk and by nearly $5 \%$ among all participants. Web-based HRA could improve CVD risk in similar populations. Future research should focus on the persistence of the effects underlying the CVD risk reduction.

Keywords: primary prevention, health risk assessment, cardiovascular disease risk

\section{Introduction}

Cardiovascular disease (CVD) represents the majority of the chronic disease burden in Europe. ${ }^{1}$ Major causal risk factors include an unhealthy diet, physical inactivity, smoking, high blood pressure, dyslipidemia, high plasma glucose, and being overweight. ${ }^{2,3}$ The CVD burden could be greatly reduced by adequately addressing these risk factors. ${ }^{4} \mathrm{~A}$ health risk assessment (HRA) is one of the most widely used strategies in the primary prevention of CVD. The worksite has been proposed as a suitable platform for such programs, with the advantage of cost savings, the creation of a health-conscious environment, and easier follow-up of high-risk individuals. ${ }^{5,6}$ 
The traditional HRA screened for risk factors to produce feedback that predominantly contained information on the assessed risk. ${ }^{7}$ However, reviews of the literature did not always support the effectiveness of the traditional HRA. ${ }^{7,8}$ It was theorized that HRA with feedback that merely contains risk information would be insufficient to promote health. ${ }^{9}$ The impact of the traditional HRA also remained unsatisfying as a consequence of suboptimal delivery due to resource constraints, limited access to high-risk populations, and no uniformity. ${ }^{7,8}$ It was acknowledged that the impact of HRA programs could be enhanced by Web-based delivery of the HRA, with incorporation of tailored health advice, aiming to reduce disease risk..$^{9-12}$

In the present study we evaluated CVD risk changes among employees who voluntarily participated in a Web-based HRA including tailored feedback that was offered to them by their employer as part of a worksite health management program. The HRA was designed to collect data that are necessary to screen for the risk of a number of preventable diseases, including CVD, and provide tailored feedback in order to educate, motivate, and empower participants in CVD risk reduction. The primary aim was to measure whether CVD risk was improved after participation in the program at a Dutch worksite.

\section{Materials and methods Study setting, design, and flow}

We conducted a prospective follow-up study among employees of a Dutch company in the services sector who voluntarily completed a Web-based HRA including tailored feedback. The HRA was applied as part of the worksite health management program in the company in 2008. During this period, 2149 employees were invited to complete the HRA. Email invitations were sent by the human resources department, with a single reminder after 2 weeks. Employees were informed that participation was voluntary, at no cost, that all personal data would be treated confidentially, and that no results would be shared with their employer or any other party. Before invitation, employees were divided into an early $(n=1108)$ and late $(n=1041)$ invitation group, based on date of birth (Figure 1).

The early invitation group was invited immediately to participate in the HRA. Employees of the early invitation group who completed the HRA and received their tailored health advice were re-invited for follow-up measurements 6 months after completion. They were not informed about follow-up measurements until the moment of re-invitation. Employees of the late invitation group were invited 6 months after the early invitation group was invited. Their baseline measurements were used to assess potential changes in CVD risk factor levels as a consequence of company-wide changes in health consciousness. If present, these temporal changes would have led to overestimation of the effects of the HRA program. The study was approved by the Medical Ethics Committee of the Academic Medical Center in Amsterdam, the Netherlands.

\section{Study intervention: web-based HRA with tailored feedback}

The studied program consisted of i) a multicomponent Web-based HRA and ii) individually tailored health advice, presented to participants as a Web-based health action plan. The HRA included i) a Web-based electronic questionnaire, ii) a biometric evaluation, and iii) a laboratory evaluation, targeting chronic disease risk, including CVD. Biometrics and collection of samples for laboratory evaluation were conducted by a licensed occupational health services provider. Results of the assessment were translated into low-, intermediate-, or high-risk profiles for the targeted disorders. By a computer-based combination of the risk profiles with health-behavior concepts, individually tailored health advice was generated. Underlying health behavior concepts include the transtheoretical model, ${ }^{13}$ protection motivation theory, ${ }^{14}$ and social cognitive theory. ${ }^{15}$ The Web-based health action plans addressed health behavior (physical activity, smoking cessation, alcohol intake, dietary habits) and included referral for further evaluation and treatment for those at high CVD risk. Risk factor cutoff values were based on the European and Dutch guidelines for cardiovascular risk management. ${ }^{16,17}$ On request, participants could schedule a 30-minute health counseling session with the program physician.

\section{Baseline measurements}

In the present study, all early and late participants completed the Web-based electronic questionnaire as part of their HRA. The questionnaire included sociodemographics, family history of CVD, personal medical history, current treatment, and current lifestyle. Physical activity was measured with the Dutch version of the International Physical Activity Questionnaire. ${ }^{18}$ Dietary habits and alcohol consumption were measured according to the standard nutrition and alcohol consumption questionnaire of the Dutch Municipal Health Service. ${ }^{19}$ Smoking behavior was measured with the Dutch Expert Center on Tobacco Control questionnaire. ${ }^{20}$ The questionnaire also addressed the health behavior change stage according to the transtheoretical model. ${ }^{13}$ This model suggests that changes in 


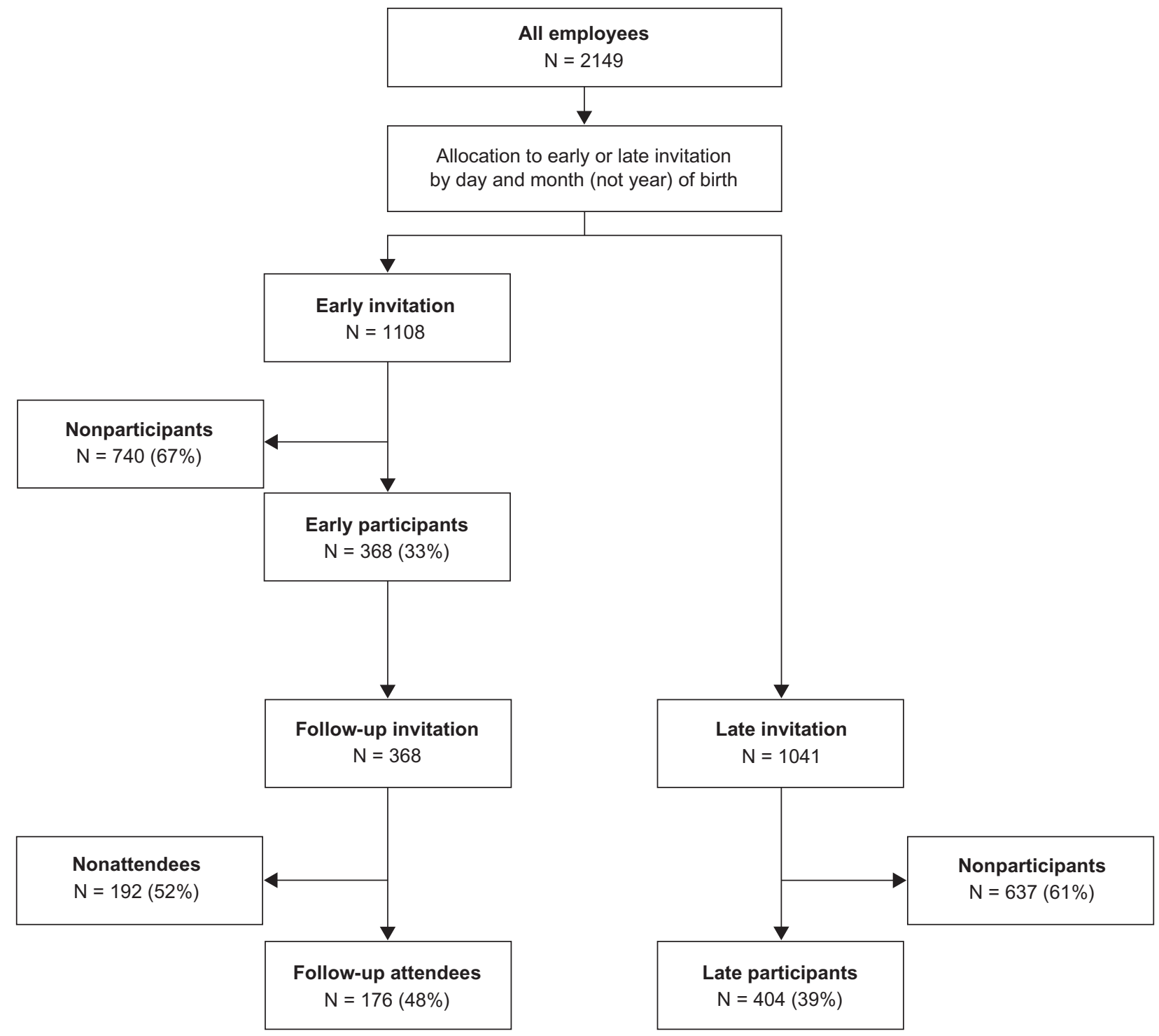

Figure I Study flow.

Notes: The HRA program was applied as part of the worksite health management program in a Dutch company worksite in 2008. During this period 2149 employees were invited to complete the HRA. Employees were divided by day and month of birth in an early and late invitation group. Early invitees who participated in the HRA program were invited for follow-up measurements, six months after the initial program invitation. At that same time the late invitation group was invited for their initial participation. The primary outcome was the change in CVD risk between baseline and follow-up among 176 early participants. To account for time trends, baseline variables between early and late participants were compared. Nonresponse bias was checked by comparing baseline values of 176 early participants who attended follow-up with 192 who did not.

health behavior appear in six phases from precontemplation (not intending to take action in the foreseeable future), contemplation (intending to change in the next 6 months), preparation (intending to take action in the next month), action (have made specific overt lifestyle modifications within the past 6 months), to maintenance (working to prevent relapse) and termination (is sure not to return to an old unhealthy habit). The health advice contained in the health plans was computer tailored to the stage of change of the participant.

All early and late participants in the HRA also visited the worksite occupational health service for measurement of height, weight, waist circumference, and blood pressure.
During the visit, nonfasting blood and urine samples were collected for analysis of total cholesterol, low-density lipoprotein (LDL)-cholesterol, high-density lipoprotein (HDL)-cholesterol, triglycerides, glucose, creatinin, and urinary albumin to creatinin ratio. Blood pressure was measured twice with a 2-minute interval on the left arm using an automated device (Omron M4, Omron Corp, Tokyo, Japan) after the subject had been sitting quietly for at least 5 minutes. Height was measured to the nearest centimeter and weight to the nearest 0.5 kilogram, with subjects wearing indoor clothing, without shoes, and with emptied pockets. A correction of 1 kilogram was applied in calculations. Waist circumference 
was measured with a centimeter tape, in the middle between the pelvic edge and lower rib. Collected samples were sent to a certified laboratory. Serum was centrifuged at $3000 \mathrm{G}$ for 10 minutes prior to transportation. All procedures were performed by trained nurses. The blood sample was analyzed using enzymatic kits (Roche Diagnostics).

\section{Follow-up measurements}

The early participants were re-invited for follow-up measurements 6 months after they completed their baseline HRA and received their tailored health advice. Invitations for follow-up measurements were sent by email with one reminder, by the study physician of the Academic Medical Center, University of Amsterdam, Amsterdam, the Netherlands. A follow-up visit was scheduled for measurements of weight, waist circumference, blood pressure, nonfasting total cholesterol, LDL-cholesterol, HDL-cholesterol, and triglycerides. The employees were informed of their follow-up results by the study physician.

\section{Outcomes and data analysis}

The primary outcome was the percentage change in Framingham score at 6 months relative to baseline. The Framingham score estimates CVD mortality and morbidity risk by combining age, sex, blood pressure, hypertension treatment status, total cholesterol, HDL-cholesterol, smoking, and diabetes status. ${ }^{21}$ CVD risk changes were also studied in low-, intermediate-, and high-risk subgroups, defined as CVD risk $<10 \%$, $\geq 10 \%-20 \%$, and $\geq 20 \%$. Secondary outcomes were changes in single risk factor levels at 6 months relative to baseline. For comparisons between baseline and follow-up, paired $t$-tests were used for continuous variables and McNemar's test for dichotomous variables. Analysis of variance was used to study CVD risk changes over the three CVD risk subgroups. Participants with known CVD (coronary heart disease, myocardial infarction, peripheral arterial disease, heart failure, and stroke) were excluded from the primary outcome analysis. In addition, changes in CVD risk and single risk factor levels were compared between participants who had a voluntary health counseling session additional to their Web-based health plan and those who did not, using Chi-squared tests. Nonresponse bias was checked by comparing differences in baseline values between early participants who attended for follow-up measurements and those who did not, using unpaired $t$-test for continuous variables and Chi-squared tests for dichotomous variables. These comparisons were adjusted for age and gender differences by linear and logistic regression analysis. Finally, to account for temporal trends in health consciousness as a consequence of program introduction at the worksite, baseline variables between early and late participants were compared. In these analyses, unpaired $t$-tests were used for continuous variables and Chi-squared tests for dichotomous variables. Data were analyzed using SPSS Version 17 (SPSS Inc., Chicago, IL, USA) for Windows.

\section{Results}

Of the 1108 early invited employees, 368 (33\%) participated in the Web-based HRA program, compared with 404 (39\%) of the 1041 late invited employees. Of the early participant group of 368 employees, 176 (48\%) attended for follow-up measurements at the mean follow-up time of 7 months. Table 1 summarizes all baseline values. Early participants who attended follow-up were older than those who did not (46 vs 43 years, $P<0.001$ ), had a higher CVD risk (10.2\% vs $7.5 \%, P<0.001)$, and had a higher systolic blood pressure (134.6 vs $131.0 \mathrm{~mm} \mathrm{Hg}, P=0.049$ ). After adjustment for sex and age, there were no differences in health characteristics between employees who attended for follow-up measurements and those who did not attend (see adjusted $P$-values in Table 1).

Table 2 shows the change in CVD risk at follow-up relative to baseline. Among employees with a baseline risk of $\geq 20 \%$, CVD risk decreased $17.9 \%$ (95\% confidence interval $[\mathrm{CI}]:-27.7 \%$ to $-8.2 \%, P=0.001)$. Among employees with a baseline CVD risk of $\geq 10 \%$ to $20 \%$, CVD risk decreased $4.4 \%(95 \% \mathrm{CI}-10.6 \%$ to $1.7 \%, P=0.155)$. Among employees with a CVD risk $<10 \%$, there was a decrease in CVD risk of $2.5 \%$ (95\% CI $-8.1 \%$ to $3.1 \%$, $P=0.376)$. The linear term in analysis of variance of the relative change in CVD risk score was statistically significantly different between employees in the three CVD risk categories $(P=0.014)$.

Among the follow-up attendees, 49 employees requested a voluntary health counseling session with the program physician after receiving their health plan, whereas 127 employees did not. Seven employees were referred to their primary care physician for treatment of high blood pressure. In two cases the primary care physician started pharmacologic treatment, and in five cases an existing treatment regimen was changed. The total number of employees on blood pressure medication increased nonsignificantly from $14(8 \%)$ at baseline to $16(9 \%)$ at follow-up. Treatment with statins was not initiated for any 
Table I Baseline characteristics

\begin{tabular}{|c|c|c|c|c|c|c|c|}
\hline & \multicolumn{5}{|c|}{$\begin{array}{l}\text { Early participants } \\
(n=368)\end{array}$} & \multicolumn{2}{|c|}{$\begin{array}{l}\text { Late participants } \\
(\mathrm{n}=404)\end{array}$} \\
\hline & $\begin{array}{l}\text { With follow-up } \\
(n=176)\end{array}$ & $\begin{array}{l}\text { Without follow-up } \\
(\mathrm{n}=192)\end{array}$ & $\begin{array}{l}P^{a} \\
\text { unadjusted }\end{array}$ & $\begin{array}{l}P^{\mathrm{b}} \\
\text { adjusted }\end{array}$ & $\begin{array}{l}\text { All } \\
(n=368)\end{array}$ & $\begin{array}{l}\text { All } \\
(n=404)\end{array}$ & $P^{c}$ \\
\hline Mean age (years) & $46 \pm 7.8$ & $43 \pm 7.4$ & $<0.001$ & - & $45 \pm 7.8$ & $44.5 \pm 8.45$ & 0.966 \\
\hline Male sex & $142(8 \mid \%)$ & I54 (80\%) & 0.909 & - & $296(80 \%)$ & $327(8 \mid \%)$ & 0.859 \\
\hline \multicolumn{8}{|l|}{ Education } \\
\hline Low & $2 I(12 \%)$ & $16(8 \%)$ & 0.311 & - & $37(10 \%)$ & 43 (1 I\%) & 0.918 \\
\hline Middle & $49(28 \%)$ & 45 (24\%) & & & $94(26 \%)$ & 103 (25\%) & \\
\hline High & $106(60 \%)$ & $13 \mid(68 \%)$ & & & 237 (64\%) & $258(64 \%)$ & \\
\hline History of CVD & $6(3 \%)$ & $4(2 \%)$ & 0.529 & 0.810 & $10(3 \%)$ & $6(1 \%)$ & 0.230 \\
\hline $\begin{array}{l}\text { Current medication therapy } \\
\text { for hypertension }\end{array}$ & $14(8 \%)$ & $15(8 \%)$ & 0.960 & 0.411 & $29(8 \%)$ & $26(7 \%)$ & 0.436 \\
\hline Current statin use & $8(5 \%)$ & II (6\%) & 0.608 & 0.121 & $19(5 \%)$ & $12(3 \%)$ & 0.121 \\
\hline Current diabetes medication & $3(2 \%)$ & $4(2 \%)$ & 1.000 & 0.557 & $7(2 \%)$ & $4(1 \%)$ & 0.286 \\
\hline Current smoking & $27(15 \%)$ & $32(17 \%)$ & 0.729 & 0.729 & $59(16 \%)$ & $80(20 \%)$ & 0.173 \\
\hline Systolic BP (mm Hg) & $134.6 \pm 16.64$ & $131.0 \pm 15.83$ & 0.049 & 0.176 & $132.9 \pm 16.29$ & $129.6 \pm 16.66$ & 0.006 \\
\hline Diastolic BP (mm Hg) & $81.3 \pm 10.90$ & $79.8 \pm 10.56$ & 0.162 & 0.502 & $80.5 \pm 10.73$ & $78.0 \pm 10.24$ & 0.001 \\
\hline Systolic BP $\geq \mid 40 \mathrm{~mm} \mathrm{Hg}$ & $60(34 \%)$ & $49(26 \%)$ & 0.072 & 0.225 & $106(29 \%)$ & $109(27 \%)$ & 0.295 \\
\hline Diastolic BP $\geq 90 \mathrm{~mm} \mathrm{Hg}$ & 38 (22\%) & $24(13 \%)$ & 0.020 & 0.114 & $62(17 \%)$ & $51(13 \%)$ & 0.097 \\
\hline Body mass index $\left(\mathrm{kg} / \mathrm{m}^{2}\right)$ & $25.3 \pm 3.37$ & $25.3 \pm 3.68$ & 0.967 & 0.753 & $25.3 \pm 3.53$ & $25.6 \pm 3.25$ & 0.226 \\
\hline Waist circumference $(\mathrm{cm})$ & $92.7 \pm 10.88$ & $92.6 \pm 10.31$ & 0.946 & 0.698 & $92.7 \pm 10.57$ & $93.6 \pm 10.42$ & 0.209 \\
\hline Total cholesterol $(\mathrm{mmol} / \mathrm{L})$ & $5.7 \pm 1.00$ & $5.6 \pm 0.94$ & 0.113 & 0.398 & $5.6 \pm 0.97$ & $5.7 \pm 1.05$ & 0.302 \\
\hline $\mathrm{HDL}(\mathrm{mmol} / \mathrm{L})$ & $1.4 \pm 0.35$ & $1.4 \pm 0.37$ & 0.484 & 0.215 & $1.4 \pm 0.36$ & $\mathrm{I} .5 \pm 0.60$ & 0.080 \\
\hline LDL (mmol/L) & $3.6 \pm 0.86$ & $3.5 \pm 0.89$ & 0.063 & 0.178 & $3.6 \pm 0.88$ & $3.5 \pm 0.91$ & 0.691 \\
\hline Triglycerides (mmol/L) & $1.62 \pm 0.98$ & $1.5 \pm 0.82$ & 0.238 & 0.448 & $1.6 \pm 0.90$ & $1.7 \pm 1.30$ & 0.011 \\
\hline $\begin{array}{l}\text { Framingham I0-year CVD } \\
\text { risk score }(\%)^{c}\end{array}$ & $10.2 \pm 8.55$ & $7.5 \pm 6.65$ & $<0.001$ & 0.182 & $8.8 \pm 7.72$ & $8.7 \pm 7.19$ & 0.964 \\
\hline
\end{tabular}

Notes: Values are expressed as mean \pm SD or number of participants (\%). ap for difference in baseline value between early participants with and without follow-up for selection analysis. Analyses for differences in baseline systolic and diastolic blood pressure, body mass index, waist circumference, total cholesterol, HDL, LDL, triglycerides, and Framingham scores were adjusted for age and sex using linear regression with the variable of interest as dependent variable and age, sex, and attending for follow-up measurements as covariates. Analyses for differences in history of CVD, current medication for hypertension, current statin use, current diabetes medication, current smoking, systolic blood pressure $\geq 140 \mathrm{~mm} \mathrm{Hg}$, and diastolic blood pressure $\geq 90 \mathrm{~mm} \mathrm{Hg}$ were adjusted for age and sex using logistic regression with the variable of interest as dependent variable and age, sex and attending for follow-up measurements as covariates. ${ }^{b} P$ for difference in baseline value between early and late participants for time trend analysis. 'Participants with a known history of CVD were excluded from the Framingham risk analysis.

Abbreviations: BP, blood pressure; CVD, cardiovascular disease; HDL, high-density lipoprotein; LDL, low-density lipoprotein; SD, standard deviation.

employee. There were no statistically significant differences in changes in Framingham risk between employees who had health counseling and those who did not.

Table 3 summarizes the changes in single risk factor levels. Systolic blood pressure was reduced by $5 \mathrm{~mm} \mathrm{Hg}(P<0.001)$,
HDL-cholesterol increased by $0.1 \mathrm{mmol} / \mathrm{L}(P<0.001)$, and waist circumference reduced by $2 \mathrm{~cm}(P<0.001)$. Changes in number of smokers, body mass index, and diastolic blood pressure were not statistically significant. There was a slight but statistically significant increase in total cholesterol with

Table 2 Changes in cardiovascular disease (CVD) risk among employees who voluntarily participated in the Web-based health risk assessment and attended follow-up measurements at a mean of 7 months

\begin{tabular}{|c|c|c|c|c|c|c|}
\hline & $\mathbf{N}$ & $\begin{array}{l}\text { CVD risk (\%) } \\
\text { at baseline }\end{array}$ & $\begin{array}{l}\text { CVD risk (\%) } \\
\text { at follow-up }\end{array}$ & Relative change $^{a}$ & $P^{b}$ & $P^{c}$ \\
\hline CVD risk changes in all study participants & $170^{d}$ & $10.2 \pm 8.55$ & $9.4 \pm 7.97$ & $-4.9(-8.9$ to -0.9$)$ & 0.017 & \\
\hline \multicolumn{7}{|c|}{ CVD risk changes in high-, intermediate-, and low-risk categories: } \\
\hline Framingham 10 -year CVD risk $\geq 20 \%$ & 21 & $28.4 \pm 7.63$ & $23.7 \pm 10.61$ & $-17.9(-27.7$ to -8.2$)$ & 0.001 & 0.014 \\
\hline Framingham I0-year CVD risk $\geq 10 \%$ to $<20 \%$ & 43 & $13.6 \pm 2.74$ & $13.0 \pm 3.65$ & $-4.4(-10.6$ to 1.7$)$ & 0.155 & \\
\hline Framingham I0-year CVD risk $<10 \%$ & 106 & $5.2 \pm 2.70$ & $5.1 \pm 3.29$ & $-2.5(-8.1$ to 3.1$)$ & 0.376 & \\
\hline
\end{tabular}

Notes: Values are expressed as mean CVD risk score percentage \pm standard deviation and mean relative differences in percentages. ${ }^{2}$ Relative difference in value between follow-up and baseline ( $95 \%$ confidence interval); ${ }^{D P}$ for effects within category; ${ }^{c}$ f from linear term in analysis of variance. ${ }^{d}$ Six participants with a known history of CVD were excluded from the analysis. 
Table 3 Changes in risk factors among employees who voluntarily participated in the Web-based health risk assessment and attended follow-up measurements at a mean of 7 months

\begin{tabular}{|c|c|c|c|c|}
\hline & \multicolumn{3}{|c|}{ Follow-up attendees $(n=176)$} & \multirow[t]{2}{*}{$P$} \\
\hline & At baseline & At follow-up & Change $^{a}$ & \\
\hline Current smoking & $27(15 \%)$ & $22(13 \%)$ & $-5-$ & 0.060 \\
\hline Systolic blood pressure $(\mathrm{mm} \mathrm{Hg})$ & $134.6 \pm 16.64$ & $129.6 \pm 14.93$ & $-5.0(-6.8$ to -3.3$)$ & $<0.001$ \\
\hline Diastolic blood pressure $(\mathrm{mm} \mathrm{Hg})$ & $81.3 \pm 10.90$ & $81.1 \pm 9.78$ & $-0.2(-1.3$ to 0.8$)$ & 0.692 \\
\hline Body mass index $\left(\mathrm{kg} / \mathrm{m}^{2}\right)$ & $25.3 \pm 3.37$ & $25.2 \pm 3.38$ & $-0.1(-0.2$ to 0.04$)$ & 0.161 \\
\hline Waist circumference $(\mathrm{cm})$ & $92.7 \pm 10.88$ & $90.7 \pm 10.63$ & $-2.0(-2.7$ to -1.4$)$ & $<0.001$ \\
\hline Total cholesterol (mmol/L) & $5.7 \pm 0.99$ & $5.9 \pm 1.01$ & $0.2(0.1$ to 0.3$)$ & 0.001 \\
\hline High-density lipoprotein (mmol/L) & $1.4 \pm 0.35$ & $1.5 \pm 0.37$ & $0.1(0.03$ to 0.1$)$ & $<0.001$ \\
\hline Low-density lipoprotein (mmol/L) & $3.6 \pm 0.86$ & $3.6 \pm 0.87$ & $0.0(-0.1$ to 0.1$)$ & 0.971 \\
\hline Triglycerides (mmol/L) & $1.6 \pm 0.98$ & $1.7 \pm 0.95$ & 0.1 (0.1 to 0.2$)$ & 0.025 \\
\hline
\end{tabular}

Notes: Values are expressed as mean \pm standard deviation or number of participants (\%) and absolute change between baseline and follow-up. absolute difference in value between follow-up and baseline ( $95 \%$ confidence interval).

$0.2 \mathrm{mmol} / \mathrm{L}(P<0.001)$ and triglycerides with $0.1 \mathrm{mmol} / \mathrm{L}$ $(P=0.025)$.

Early and late participants were similar in age, sex, education, ethnicity, medical history, and medication use at baseline (see right panel of Table 1). Baseline systolic blood pressure of late participants was $3.3 \mathrm{~mm} \mathrm{Hg}$ lower than that of early participants, and diastolic blood pressure was $2.5 \mathrm{~mm} \mathrm{Hg}$ lower. Framingham risk scores, however, were similar between early and late participants.

\section{Discussion}

We observed a significant decrease in CVD morbidity and mortality risk among employees at a single Dutch worksite who voluntarily completed a Web-based HRA and received tailored health advice, as measured by Framingham scores after 7 months. There was a graded relation between CVD risk reduction and baseline CVD risk. The decrease was highest among those at greatest risk, with a $17.9 \%$ relative reduction in the high-risk subgroup, and lower among those at intermediate and low risk.

The reduction in CVD risk was mainly due to reduced systolic blood pressure $(-5.0 \mathrm{~mm} \mathrm{Hg}$ reduction), whereas no beneficial effects were found for total cholesterol, triglycerides, and LDL-cholesterol. Because the observed beneficial changes were not explained by additional health counseling, referral to primary care physicians, or medication, and given that improvements in physical activity and diet can be effective in both reducing blood pressure and increasing HDL, ${ }^{22-25}$ we believe that the observed effect is explained by lifestyle improvements induced by the individualized advice that each participant received.

A number of systematic reviews showed that multicomponent prevention programs delivered at the worksite reduced
CVD risk factors. ${ }^{26-28}$ The greatest effect appeared in those at greatest risk, in accordance with our findings. ${ }^{26}$ Few studies used global CVD risk as an outcome measure for effectiveness of multicomponent risk factor intervention programs. These studies reported global risk reductions ranging from $2 \%$ to $14 \%$, which are consistent with our findings. ${ }^{29-33}$

The design of our study enabled us to check for temporal trends as a consequence of program introduction at the worksite. We found that mean systolic blood pressure and diastolic blood pressure were lower among late participants when compared with early participants. This suggests a background effect of an increased health consciousness within the company, possibly as a consequence of program introduction. However, the mean overall CVD risk score was similar in early and late participants. Moreover, the proportion of participants at high systolic or diastolic blood pressure was also not different in the two groups. Therefore, although a background effect cannot be ruled out completely, its magnitude is marginal.

Our study has several limitations. First, participation in the studied HRA program was voluntary, with participation rates of 33\% among the early participants and 39\% among the late participants. Studies that evaluated HRA or health promotion programs reported participation rates from $20 \%$ to $76 \%,,^{34,35}$ with the general impression that females, older employees, and mainly the worried well were attracted. ${ }^{36}$ Although the participation rate in this study was as expected, we cannot rule out that among nonparticipants in the HRA program there were employees with more or less favorable health characteristics. Furthermore, of the early participants who were eligible for study measurements, about half completed follow-up. However, after adjustment for differences in age and gender, there were no differences 
between follow-up attendees and nonattendees. Therefore, we believe that the outcomes of our study were not skewed by selection and are valid among employees who voluntarily participated in the HRA program. Second, ideally, CVD risk in late participants would also have been measured 6 months before the beginning of their program. In this way their measurements could have served as a rigorous control for early participants. Unfortunately, we were not able to do an early measurement in late participants. Nevertheless, the absence of a clinically relevant background effect supports the conclusion that the differences observed in the early participants can be attributed to participation in the program. Third, we did not have data on whether employees regularly visited their primary care physician outside the HRA program. Although additional physician counseling after tailored feedback within the program did not influence Framingham risk, we cannot completely rule out that some improvements could be from usual primary care management and not from the HRA. Finally, participants in the program were predominantly well-educated male employees. Therefore, our findings may be applicable only to comparable populations. However, as the impact of the HRA program was proportional to the absolute level of CVD risk, the program may be more effective in other, less educated populations.

In summary, voluntary participation in a Web-based HRA with tailored feedback at the worksite reduced CVD morbidity and mortality risk by nearly $18 \%$ among participants at high risk for CVD and by nearly 5\% among all participants. It is important to note that this risk reduction is realized with an easy-to-replicate, low-cost, Web-based delivered program, mostly with motivational and educational health advice and without initiation of pharmacologic therapy. Future research should focus on the persistence of these effects.

\section{Acknowledgment}

We thank all employees of the study worksite for their participation.

\section{Authors' contributions}

RJGP and JGPT were the principal investigators of the study, developed the concept and design of the study, and contributed to the interpretation of data. EBC carried out the data collection. EBC and BF performed the data analyses, and drafted the manuscript. RK and CVK participated in coordination of the study and drafting the article. All authors reviewed a previous version of the manuscript and vouch for the accuracy and completeness of the data and analyses.

\section{Disclosure}

Drs RAK and CVK are directors at NDDO Institute for Prevention and Early Diagnostics (NIPED). The institute developed the studied program and currently markets it in the Netherlands. For the present study, NIPED provided for a PhD grant for EBC and BF. RJGP and JGPT are employed by the Academic Medical Center, University of Amsterdam, Amsterdam, the Netherlands. They received no additional funding for this study and declare that there are no conflicts of interest. A PhD grant was funded for EBC and BF. Study materials were funded by NIPED.

\section{References}

1. Allender S, Scarborough P, Peto V, et al. European Cardiovascular Disease Statistics 2008. British Heart Foundation Health Promotion Research Group. Oxford, UK: Department of Public Health, University of Oxford; 2008.

2. Yusuf S, Hawken S, Ounpuu S, et al. Effect of potentially modifiable risk factors associated with myocardial infarction in 52 countries (the INTERHEART study): case-control study. Lancet. 2004;364: 937-952.

3. World Health Organization. Preventing Chronic Diseases: a Vital Investment - WHO global report. Geneva, Switzerland: World Health Organization; 2005.

4. Yach D, Hawkes C, Gould CL, Hofman KJ. The global burden of chronic diseases: overcoming impediments to prevention and control. JAMA. 2004;291:2616-2622.

5. Carnethon M, Whitsel LP, Franklin BA, et al. Worksite wellness programs for cardiovascular disease prevention: a policy statement from the american heart association. Circulation. 2009;120: $1725-1741$.

6. Goetzel RZ, Ozminkowski RJ. The health and cost benefits of work site health-promotion programs. Annu Rev Public Health. 2008;29: 303-323.

7. Soler RE, Leeks KD, Razi S, et al. A systematic review of selected interventions for worksite health promotion. The assessment of health risks with feedback. Am J Prev Med. 2010;38:S237-S262.

8. Anderson DR, Staufacker MJ. The impact of worksite-based health risk appraisal on health-related outcomes: a review of the literature. Am J Health Promot. 1996;10:499-508.

9. Cowdery JE, Suggs LS, Parker S. Application of a Web-based tailored health risk assessment in a work-site population. Health Promot Pract. 2007;8:88-95.

10. Kreuter MW, Strecher VJ. Do tailored behavior change messages enhance the effectiveness of health risk appraisal? Results from a randomized trial. Health Educ Res. 1996;11:97-105.

11. Kreuter MW, Strecher VJ, Glassman B. One size does not fit all: the case for tailoring print materials. Ann Behav Med. 1999;21: 276-283.

12. Noar SM, Benac CN, Harris MS. Does tailoring matter? Meta-analytic review of tailored print health behavior change interventions. Psychol Bull. 2007;133:673-693.

13. Prochaska JO, Velicer WF. The transtheoretical model of health behavior change. Am J Health Promot. 1997;12:38-48.

14. Floyd DL, Prentice-Dunn S, Rogers RW. A meta-analysis of research on protection motivation theory. J Appl Soc Psychol. 2000;30: 407-429.

15. Bandura A. Self-efficacy: the Exercise of Control. New York, NY, USA: WH Freeman and Co; 1997.

16. The Dutch Institute for Healthcare Improvement $\mathrm{CBO}$ and Dutch College of General Practitioners. Multidisciplinary Guideline Cardiovascular Risk Management. Utrecht, the Netherlands: van Zuiden Communications; 2006. 
17. Graham I, Atar D, Borch-Johnsen K, et al. European guidelines on cardiovascular disease prevention in clinical practice: executive summary. Eur Heart J. 2007;28:2375-2414.

18. Craig CL, Marshall AL, Sjostrom M, et al. International physical activity questionnaire: 12-country reliability and validity. Med Sci Sports Exerc. 2003;35:1381-1395.

19. Van den Brink CL, Ocke MC, Houben AW, et al. Validering van Standaardvraagstelling Voeding voor Lokale en National Monitor Volksgezondheid (RIVM Rapport 260854008) [Validation of a Community Health Services Food Consumption Questionnaire in the Netherlands]. Bilthoven, the Netherlands: Rijksinstituut voor Volksgezondheid en Milieu (RIVM); 2005.

20. Mudde AN, Willemsen MC, Kremers S, de Vries H. Meetinstrumenten voor Onderzoek Naar Roken en Stoppen met Roken. [Measurements for Research on Smoking and Smoking Cessation]. Den Haag, the Netherlands: STIVORO; 2000.

21. D’Agostino RB Sr, Vasan RS, Pencina MJ, et al. General cardiovascular risk profile for use in primary care: the Framingham Heart Study. Circulation. 2008;117:743-753.

22. Cooper AR, Moore LA, McKenna J, Riddoch CJ. What is the magnitude of blood pressure response to a programme of moderate intensity exercise? Randomised controlled trial among sedentary adults with unmedicated hypertension. Br J Gen Pract. 2000;50: 958-962.

23. Ebrahim S, Smith GD. Lowering blood pressure: a systematic review of sustained effects of non-pharmacological interventions. J Public Health Med. 1998;20:441-448.

24. John JH, Ziebland S, Yudkin P, et al. Effects of fruit and vegetable consumption on plasma antioxidant concentrations and blood pressure: a randomised controlled trial. Lancet. 2002;359: 1969-1974.

25. Sacks FM, Svetkey LP, Vollmer WM, et al. Effects on blood pressure of reduced dietary sodium and the Dietary Approaches to Stop Hypertension (DASH) diet. DASH-Sodium Collaborative Research Group. N Engl J Med. 2001;344:3-10.
26. Ebrahim S, Beswick A, Burke M, Davey SG. Multiple risk factor interventions for primary prevention of coronary heart disease. Cochrane Database Syst Rev. 2006;CD001561.

27. Heaney CA, Goetzel RZ. A review of health-related outcomes of multi-component worksite health promotion programs. Am J Health Promot. 1997;11:290-307.

28. Pelletier KR. A review and analysis of the clinical and cost-effectiveness studies of comprehensive health promotion and disease management programs at the worksite: update VII 2004-2008. J Occup Environ Med. 2009;51:822-837.

29. Ellsworth DL, O’Dowd SC, Salami B, et al. Intensive lifestyle modification: impact on cardiovascular disease risk factors in subjects with and without clinical cardiovascular disease. Prev Cardiol. 2004; 7:168-175.

30. Maruthur NM, Wang NY, Appel LJ. Lifestyle interventions reduce coronary heart disease risk: results from the PREMIER trial. Circulation. 2009;119:2026-2031.

31. Mendivil CO, Cortes E, Sierra ID, et al. Reduction of global cardiovascular risk with nutritional versus nutritional plus physical activity intervention in Colombian adults. Eur J Cardiovasc Prev Rehabil. 2006;13:947-955.

32. Richardson G, van Woerden HC, Morgan L et al. Healthy hearts: a community-based primary prevention programme to reduce coronary heart disease. BMC Cardiovasc Disord. 2008;8:18.

33. Wister A, Loewen N, Kennedy-Symonds H, et al. One-year follow-up of a therapeutic lifestyle intervention targeting cardiovascular disease risk. CMAJ. 2007;177:859-865.

34. Dobbins TA, Simpson JM, Oldenburg B, et al. Who comes to a workplace health risk assessment? Int J Behav Med. 1998;5:323-334.

35. Robroek SJ, van Lenthe FJ, van EP, Burdorf A. Determinants of participation in worksite health promotion programmes: a systematic review. Int J Behav Nutr Phys Act. 2009;6:26.

36. Lerman Y, Shemer J. Epidemiologic characteristics of participants and nonparticipants in health-promotion programs. J Occup Environ Med. $1996 ; 38: 535-538$
Vascular Health and Risk Management

\section{Publish your work in this journal}

Vascular Health and Risk Management is an international, peerreviewed journal of therapeutics and risk management, focusing on concise rapid reporting of clinical studies on the processes involved in the maintenance of vascular health; the monitoring, prevention and treatment of vascular disease and its sequelae; and the involvement of

\section{Dovepress}

metabolic disorders, particularly diabetes. This journal is indexed on PubMed Central and MedLine. The manuscript management system is completely online and includes a very quick and fair peer-review system, which is all easy to use. Visit http://www.dovepress.com/ testimonials.php to read real quotes from published authors. 